\title{
A Comprehensive Review of E-HRM in Service SMEs in Jordan
}

\author{
Nader Abu Roman ${ }^{1}$ \\ ${ }^{1}$ CQ University, Australia \\ Correspondence: Nader Abu Roman, CQ University, Australia. \\ Received: December 7, 2016 \\ Accepted: February 14, 2017 \\ Online Published: April 18, 2017 \\ doi:10.5539/ibr.v10n5p116 \\ URL: https://doi.org/10.5539/ibr.v10n5p116
}

\begin{abstract}
This article reviews current empirical studies on electronic Human Resource Management (E-HRM) in SMEs in Jordan and discuss some findings for future undertakings. The comprehensive review is composed of related studies extracted from the online index or data base of the various journals. Contextual structure had been presented to have a clear mapping and understanding with the proceedings. It also included some studies of E-HRM outside Jordan to supplement the insufficiency and reliability of the comprehensive review. Conclusion and recommendation had been made.
\end{abstract}

Keywords: E-HRM, SMEs, Jordan, comprehensive review, effects and benefits of E-HRM, implementation of E-HRM

\section{Introduction}

Generally, increasing evidence shows that SME's show a relevant function in the societal economic development of any country. SME's bring out most of current jobs and provide much of the resourcefulness and innovation that hike economic progress. The small and medium sized enterprises helps boost up the economy in Jordan. The strategies to invite, pay out, motivate and retain employees are becoming a dismaying task SME's as the battle for talent and skills become extremely competitive. The challenges of Human Resource Management (HRM) are higher now due to the complication in which organisations operate and function. The human resources or intellectual capital has emerged as main component in a company's future success (Abraham, et. al., 2014).

The term E-HRM connotes different meaning to any individuals in the Small and Medium Enterprises. But it is strongly defined as, a web-based result that takes advantage of the newest web application technology to give an online real-time HRM Solution. It is systematic and easy to use, feature-rich yet formative enough to answer to one's specific needs. Of all the resources, human capital is the most vital wealth because every activity in the business is controlled by them. In any business firm: service or industrial sector requires men. The main duty of the HRM is to build an effective selective instrument and functions by the aid of information technology. The traditional way which is HRM transform into E-HRM. It speeds up the velocity of information flows and can manipulate multiple tasks and serves as a tool of wise decision making. The integration of HR and technology helps in leveraging the HR activities and automating transactions related to recruitment, performance tracking, career planning and training. This means that they play complementary functions (Varma 2010).

\subsection{Layout}

This paper is organized as follows. The process involves reviews of the research or studies on E-HRM Services in SME's in Jordan and creates framework that could aid to a better explanation of some of the reviewed issues. There upon, framework is being used to analyse the studies described. It is followed by the presentation of the results of the analysis. Next to it is the related reviews and studies outside the country. After which, is the discussion section that links the results with the existing research and proposes future research directions. Finally, the conclusion wraps up the comprehensive review by reflecting on the findings.

\section{The Screening Methods}

The main purpose of this paper is to present a comprehensive review of information accumulated from the studies and journals from 2007 up to the present regarding Electronic-Human Resource Management (E-HRM) in service of Small and Medium Enterprises (SMEs) in Jordan. Of One hundred fifty-five (155) studies and readings scanned and reviewed in the web data base of European Journal, International Journal of Management 
Reviews, Management and Service, International Journal of Business and Science, Research Gate, International Conference on Innovation, Linked in, Australian Journal of Basic and Applied Sciences, Asian Social Science and Academia only seven (7) studies support the comprehensive review. Some were neglected due to its irrelevancy to the comprehensive review and some were already obsolete. The seven (7) studies and reviews were accordingly satisfied and supported the inclusion criteria. Extracted data are: Level of Implementation of E-HRM; Benefits of the Use of E-HRM; Perceived Barriers of the Use of E-HRM and Effects of E-HRM in SME's In Jordan. The following related studies are Rawash 2012, Al-Dmour, et. al and 2012, Khasman, et al. (2015), Elhazzam (2015), Ayeta (2016), Ngai and Wat, 2006 and Marler (2009).

\section{Contextual Framework}

The comprehensive review reveals that e-HRM practice contains several entities that could affect the services in SME's in Jordan. Therefore examining those topics could help us understand how and why they affect the outcomes of the systems. To be able to map the current topics of the literature that discussed before, this section articulates a general framework that will later be used to identify the impact of E-HRM to SME's in Jordan as it is stipulated in Figure 1. In particular, this framework will be used as a part of a concept centric approach to review the E-HRM literature in hopes of new insight into understanding the positive or negative effect of E-HRM in the SME's in Jordan.

There are two reasons behind the rationale of the selection of framework is based on two reasons. Primarily, the inadequacy of standardisation on E-HRM allows any scheme to deliver some levels of understanding about the particular situation. The second component that appears in the scheme is also identified in E-HRM research as some of the reasons that affect organisation transformations (Strohmeier, 2007). Thus, the seek to examine how outcomes around E-HRM of SME's in Jordan are affected by factors such as: Level of Implementation of E-HRM; Benefits of the Use of E-HRM; Perceived Barriers of the Use of E-HRM and the effect of E-HRM. By assessing and evaluating those factors, it gives a clear understanding with the impact of E-HRM in the country and how or why those perceptions materialize.

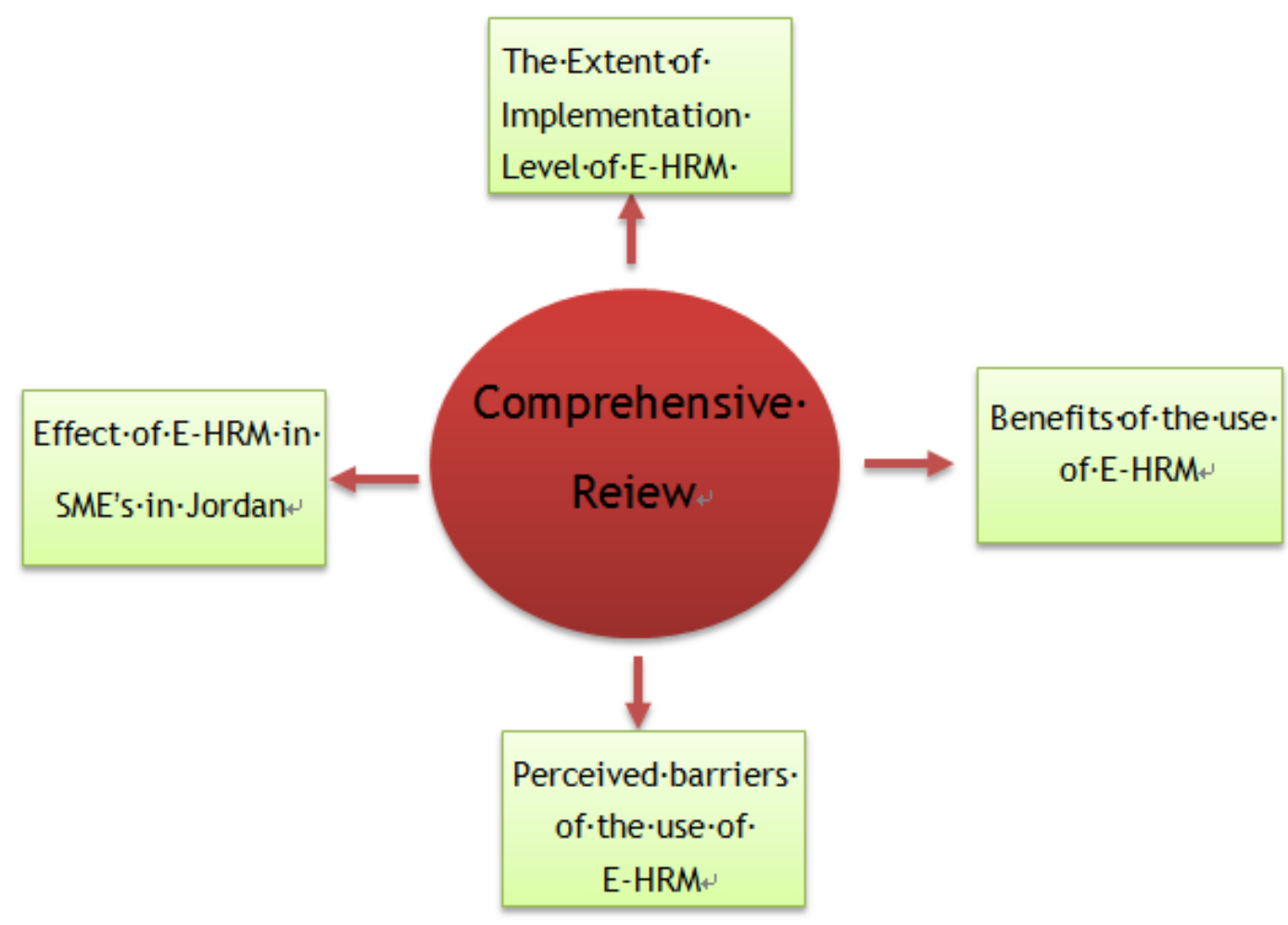

Figure 1. Contextual Framework 


\section{Data Anal ysis and Results}

At this part, it shows results which were already statistically treated and analysed.

\subsection{The Degree of Implementation Level of E-HRM Functions}

This section demonstrates the descriptive analysis for the level of implementation of E-HRM functions. Al-Dmour, et. al 2012 reveals that there are a moderate level of E-HRM functions in shareholding enterprises since the result are more than the mean of the scale which is (3). The result of $61.2 \%$ refers to the level of implementation which indicates moderate implementation of E-HRM. Recruitment and selection, employee record keeping, internal and external communication respectively are the highest levels of implementation. According to the study of Marler (2009), Strong Implementation of e-HRM is identified with perceptions of strategic effectiveness of HR. It is both positive and negative perceptions.

\subsection{Benefits of the Use of E-HRM}

In the data analysis of the study of Al-Dmour 2015, he detailed the results in Table 12 (p. 220) that T-Value is 5.239 and the Sig. is .000 . It is seemingly obvious from the results that adopters' group are more positive than non-adopters with regards to the perceptions of the advantages of E-HRM applications .The group of the enterprise who adopts E-HRM are attached more importance to the benefits of E-HRM in its capacity of facilitating the recruitment proceeds, organising HR process and reducing data re-entry and other benefits with the exceptions of high levelling competitiveness and creating wise decision making. According to Ayeta (2016), the e-benefits approach utilises the web to deliver information on the benefits of the employees; reading the costs for delivering, streamlining, benefits from administration, enhancing employee access and empowering employees' access to benefits information.

\subsection{Perceived Barriers of the Use of E-HRM}

As shown in Table (13) demarcates between the two groups based on their impulse towards the barriers restricting them from the use E-HRM applications in their enterprises. Conferring with t-test and mean results, it was concluded that the adopters' group are relatively different from the non-adopters' group with regards to their perceptions of obstacles inhibiting their companies from the use of E-HRM applications. The non-adopters' group has ranked highest of the following barriers compare to their counterpart: insufficient time to do the necessary analysis to determine the process to automate, Lack of knowledge in implementing the system, the management is not oriented with the technology behind IT applications in E-HRM, and the staffs do not have relevant knowledge and skills for E-HRM applications (Al-Dmour 2015). However, another study shows that the E-HRM adoption shows that many enterprises have problems when utilising new technologies including E-HRM due to numerous barriers which include lack of sufficient capital and skills (Ngai and Wat, 2006).

\subsection{Effect of E-HRM}

The data analysis of Khashman (2015) presented the analysis in the Tables 4, 5, 6 and 7 (p. 125 of his study, the $\mathrm{F}$ value is 13.36 with a significance equal 0.00 , which is less than $(0.05)$. this signifies, there is an effect of E-HRM practices as one of the operational performance dimensions. Furthermore, $8.60 \%$ of the variance in cost noted for E-HRM practices, 20.47 is the F value with a significance equal to 0.00 , which is less than (0.05).It means that there is an effect of E-HRM practices on cost. The variance of $5.32 \%$ in "Quality of service" accounted by "E-HRM practices", the $F$ value is 9.03 with a significance equal to 0.00 , which is less than (0.05).For this reason, there is an effect of E-HRM practices on Quality of service. For Flexibility, the variance is $4.78 \%$, the $\mathrm{F}$ value is 6.76 with a significance equal to 0.00 , which is less than $(0.05)$.Significantly, there is an effect of E-HRM practices on flexibility. The connotation of the finding for the Jordanian Enterprises is that they need to pursue a combined strategy aimed at E-HRM practices to improve operational performance. The E-HRM practices and operational performance were significantly related since findings revealed that E-HRM practices had a positive impact on Time, Cost, Quality service and Flexibility. Elhazzam (2015) discussed that ICT contributes a significant and positive effect on Human resource management Practices, the ICT regression coefficient $(\beta=0.868, \mathrm{P}=000)$. Based on the outcome the study hypothesis was accepted which indicated a significant effect of ICT on Human resource management Practices at level of $(\mathrm{P} \leq 0.05)$.

4.5 Other Related Review of Electronic- Human Resource Management in Services in SME's Outside the Country

This section of the paper presents the related proceedings to support the insufficient comprehensive reviews regarding the E-HRM in Jordan in SMEs. This is to support the impact of adoption of technology advancement in the field of HRM in the country. 
Statistical treatment results that Malaysian SMEs recruitment policies are made primarily by highest rank in the management. It has shown that production systems, quality management and automation are prime domains of SMEs operations to be used in an e-business system, but HRM and recruitment are part of future planning. In Malaysian SME E-HRM is mainly for speeding up system to enable SMEs to deal with multi-cultural and multi-lingual working situation and that make employees and job seekers improve its communication and interaction (Poorang 2012). According to the Ministry of Manpower, Singapore, e-HRM initiatives could be introduced with an initial expenditure of $\$ \$ 3,000$ and few dollars for monthly cost. However, the low cost SME's could not afford to implement e-HRM initiatives (Rowly, et. al 2007). Moreover, Most of the studies have shown that only large organisations adopt E-HRM than SMEs (Kabst, 2009).

The positive and relevant result $(\beta=.279 ; \mathrm{p}<.05)$ is the effect of expectation and optimism towards technology. A further consideration in the progression model concerns the relatively low R2 $(R 2=.104)$, a justification that there are many factors, other than e-HRM practices, affect to increasing organisational commitment, while, the assumption regarding the adoption of e-HRM systems becomes significantly relevant when employees are particularly technology oriented (Bissola, et. atl. 2013). The attitude has been discovered with the basis of data analysis that it influence in the adoption of E-HRM. Subjective standards and perceived behavioural control did not give relevant effect. When making design in the implementation of methodologies and change management strategies, the information stated above is very important as interventions need to be created specifically to meet the organisation's requirement of E-HRM adoption. The research also has practical presumption especially for the function of HR department in making changes in management strategies in collaboration with other department in the company (Ramayah 2011). E-HRM contributes competitive benefits for supporting human resource management processes. It ensures easier, faster, and cheaper HR exercises accomplishment and guides in all types of operational, functional and strategic human resource management processes. It solves problem in a more effective and strategic HRM processes. All these advantages of E-HRM can be achieved easily only if the system is adopted or adapted in an organisation precisely and more effectively (Masum 2015)

\section{Discussion}

Findings indicate that the adoption of E-HRM within the sample under study is considered to be moderate. This signifies that the level of implementation of E-HRM application provides some variations among shareholdings companies. Some companies or enterprises can't deny the fact that they can't rid of using traditional method or still thinking to have such system in the future.

On the other hand, there is a significant relationship between the internal factors (organisations demographic, organisation resources, organisational sharing culture, organisation readiness and commitment, organisation's structural IT characteristics, perceived IT applications attributes /benefits of E-HRM applications, perceived obstacle to the use of E-HRM and the implementation level E-HRM in enterprises in Jordan put together. The recognised benefits of IT applications and organisation readiness and commitment are found to be the most important determinant of internal factors that are associated with the level of the implementation of E-HRM in shareholding companies.

The evaluation of the features of the perceptions of the benefits of E-HRM applications construct, findings stipulate that the group of adopters of companies was found to be more positive to all mentioned benefits of E-HRM applications than non-adopters. Moreover, the use of e-tools in medium sized organisations is perceived as useful, whereas not easy to use. The organisation perceived that the use of E-HRM helps them make HRM more effective (Bondarok, 2009). 'E-HRM provides competitive advantages for supporting human resource management processes. It ensures easier, faster, and cheaper HR activity accomplishment and helps in all types of operational, functional and strategic human resource management processes. It helps to take more effective and strategic decision to solve HR problems. All these benefits of E-HRM can be attained seamlessly only if the system is adopted or adapted in an organisation accurately and more effectively.

The findings of reviewed studies are not that valid and reliable. This is due to the lack of relevant studies related to the comprehensive review in electronic human resource management in Jordan. That is why, the author considered review findings from the studies outside Jordan.

\section{Conclusion}

The comprehensive review lacks the materials used which means that E-HRM is not common in the small and medium enterprises in Jordan. As mentioned by Kabst (2009) most of the SME's cannot take risk to afford the cost of creating E-HRM. Some of them also were not computer technology oriented. 


\section{Recommendation}

It is highly recommended that future researchers will look into considering a study which relates to the adoption of E-HRM in any enterprises or companies in Jordan.

\section{References}

Abraham, M. et. al. (2014). A Review of SMEs Recruitment and Selection Dilemma: Finding A 'Fit'.Proceedings of the Australian Academy of Business and Social Sciences Conference 2014 (in partnership with The Journal of Developing Areas). ISBN 978-0-9925622-0-5.

Ayeta, A. (2016). Impact of ICT on Human Resource Management, Academia.

Aysar, K. M. et al. (2015). The Impact of Electronic Human Resource Management (E-HRM) Practices on Business Performance in Jordanian Telecommunications Sector: "The Employees Perspective". Journal of Management Research, 7(3).

Bondarok, T. (2009). Exploring Perception about the use of E-HRM Tools in Meduim Sized Organizations. IGI Global Copy Right 2009.

Elhazzam, M. (2015). The Effect of ICT on Human Resources Management Practices. International Journal of Innovative Research in Engineering \& Management, 2(3).

Kabst, R. (2009). Organizational Adoption of E-HRM in Europe. An Empirical Exploration of Major Adoption Factors. Journal of Managerial Psychology, 24(6), 482-501. https://doi.org/10.1108/02683940910974099

Marler, J. (2009). An Evidence-Based Review of E-HRM and Strategic Human Resource Management. University at Albany-State University of New York, USA.

Ngai and Wat. (2006). Human resource information systems: A review and empirical analysis. Researcg Gate. https://doi.org/10.1108/00483480610656702

Poorangi, M. (2012). An Evaluation of the Effectiveness of E-recruitment Practices for SMEs in Malaysia. 2011 International Conference on Innovation, Management and Service IPEDR vol.14(2011) (C) (2011) IACSIT Press, Singapore.

Ramayah, T. et. al. (2011). Explaining the Intention to Use Electronic HRM among HR Professionals: Results from a Pilot Study.

Rand, H. Al-Dmour, et. al. (2012). Determinants Of The Implementation Level of Electronic Human Resources Management (E-HRM) in Jordanian Shareholding Companies European. Scientific Journal E-Issn: 1857-7431.

Rowley, C. (2007). Management in South-East Asia: Business Culture, Enterproses and Human Resources. Routledge Copy right.

Strohmeier, S. (2007). Research in E-HRM: Review and Implications, Chair for Management Information Systems. Saarland University, Postfach 151150, 66041 Saarbrücken/Germany.

Varma, S. (2010). The Implications of Implementing Electronic- Electronic Human Resource Management Human Resource Management (E-Hrm) Systems in Companies Hrm) Systems in Companies. Padmashree Dr. D.Y. Patil University, Department Of Business Management, Sector 4, Plot No. 10, Cbd Belapur, Navi Mumbai - 400614.

\section{Copyrights}

Copyright for this article is retained by the author(s), with first publication rights granted to the journal.

This is an open-access article distributed under the terms and conditions of the Creative Commons Attribution license (http://creativecommons.org/licenses/by/4.0/). 